\title{
Reconstruction of summer droughts using tree- ring cellulose isotopes: a calibration study with living oaks from Brittany (western France)
}

\author{
G. Raffalli-Delerce, V. Masson-Delmotte, J. L. Dupouey, M. Stievenard, N. \\ Breda \& J. M. Moisselin
}

To cite this article: G. Raffalli-Delerce, V. Masson-Delmotte, J. L. Dupouey, M. Stievenard, N. Breda \& J. M. Moisselin (2004) Reconstruction of summer droughts using tree-ring cellulose isotopes: a calibration study with living oaks from Brittany (western France), Tellus B: Chemical and Physical Meteorology, 56:2, 160-174, DOI: 10.3402/tellusb.v56i2.16405

To link to this article: https://doi.org/10.3402/tellusb.v56i2.16405

$$
\begin{aligned}
& \text { (c) } 2004 \text { The Author(s). Published by Taylor \& } \\
& \text { Francis. }
\end{aligned}
$$

\section{Published online: 18 Jan 2017.}

Submit your article to this journal $\pi$

$$
\text { LII Article views: } 41
$$

4 Citing articles: 4 View citing articles 준 


\title{
Reconstruction of summer droughts using tree-ring cellulose isotopes: a calibration study with living oaks from Brittany (western France)
}

\author{
By G. RAFFALLI-DELERCE ${ }^{1}$, V. MASSON-DELMOTTE ${ }^{1 *}$, J. L. DUPOUEY ${ }^{2}$, M. \\ STIEVENARD ${ }^{1}$, N. BREDA ${ }^{2}$ and J. M. MOISSELIN ${ }^{3},{ }^{1}$ Laboratoire des Sciences du Climat et de \\ l'Environnement, IPSL/CEA-CNRS, Gif-sur-Yvette, France; ${ }^{2}$ UMR Ecologie et Ecophysiologie forestière, \\ INRA-Nancy, Champenoux, France; ${ }^{3}$ Météo France, Toulouse, France
}

(Manuscript received 16 December 2002; in final form 13 June 2003)

\begin{abstract}
The aim of this study is to establish a calibration of the late wood cellulose carbon and oxygen isotopic inter-annual variability measured on four living oaks (1879-1998) in the Atlantic area (Rennes Forest, Brittany, western France) to meteorological (beginning in 1885) and hydrological (beginning in 1951) data. We find a better tree-to-tree consistency of the $\delta^{18} \mathrm{O}$ ratio, compared with that of the tree-to-tree variability of the ring width and the $\delta^{13} \mathrm{C}$ possibly affected by individual competition effects.

On a century-long time scale, the $\delta^{13} \mathrm{C}$ ratio in the cellulose reflects the globally decreasing trend of $\delta^{13} \mathrm{C}$ in atmospheric $\mathrm{CO}_{2}$, which is mainly due to fossil fuel burning. In contrast with the ring width, which here shows a weak and complex dependence on meteorological parameters, the isotopic composition of the cellulose enables a reliable reconstruction $\left(R^{2}>0.45\right)$, mainly due to the $\delta^{18} \mathrm{O}$ signal, of selected summer climatic parameters: relative humidity, soil moisture deficit and temperature. The reconstructed parameters capture both low-frequency variations and extreme dry years (summer droughts). While both summer temperature and annual mean precipitation have a long-term increasing trend, the reconstructed water stress indicators do not show a significant trend during the 20th century. On average one summer drought occurs every seven summers, but this frequency varies in parallel to decadal changes in mean summer temperature, with fewer droughts in the 1930s and 1960s-1970s and more droughts in the 1900s, 1940s and 1990s.
\end{abstract}

\section{Introduction}

In order to describe and understand the climate variability during the last few centuries, global-scale temperature reconstructions have been derived. During the pre-instrument period, these temperature syntheses rely heavily on tree-ring widths and densities, which can provide valuable and well-dated interannual climate information. However, at coastal locations, where the seasonal and interannual temperature and water stress fluctuations are small, these parameters are not clearly influenced by either summer temperature or available soil moisture. In such maritime climate areas, other proxies are necessary to obtain quantified climatic reconstructions, such as tree-ring cellulose isotopes.

The oxygen isotopic composition of the precipitation has long been used to reconstruct past changes in local condensation temperature, especially in polar regions, where the precipitation is directly preserved in ice cores in almost the original state (e.g.

\footnotetext{
* Corresponding author.

e-mail: masson@1sce.saclay.cea.fr
}

Jouzel et al., 2003). Recent results have also shown the potential of alternative archives such as lake sediments (von Grafenstein et al., 1996) or speleothems (McDermott et al., 2001), where the $\delta^{18} \mathrm{O}$ of the precipitation can be preserved during hydrological transfers and calcite formation. Obtaining reconstructions of the $\delta^{18} \mathrm{O}$ of the precipitation using a combination of various archives is possible in the North Atlantic regions, and should bring integrated information on the variability of the climate and water cycle. In this framework, tree-ring cellulose isotopic measurements offer the possibility to study the $\delta^{18} \mathrm{O}$ of the precipitation at the inter-annual scale, and to compare the relative performances of cellulose $\delta^{13} \mathrm{C}$ versus $\delta^{18} \mathrm{O}$ as climatic tracers (Edwards et al., 2000).

The $\delta^{13} \mathrm{C}$ in plant matter is determined by the $\delta^{13} \mathrm{C}$ of atmospheric $\mathrm{CO}_{2}, \delta^{13} \mathrm{C}_{\text {plant }}=\delta^{13} \mathrm{C}_{\text {atm }}-\Delta^{13} \mathrm{C}$, where $\Delta^{13} \mathrm{C}=a+$ $(b-a) p_{i} / p_{\mathrm{a}}, \Delta{ }^{13} \mathrm{C}$ is the carbon discrimination, $a$ is the fractionation due to diffusion in the air $(4.4 \% o), b$ is the fractionation caused by carboxylation $(27 \% o), p_{\mathrm{i}}$ is the $\mathrm{CO}_{2}$ partial pressure inside the leaf and $p_{\mathrm{a}}$ is its partial pressure in the atmosphere (Farquhar et al., 1989). Further isotopic fractionation through 
transient biochemical processes from the initial photosynthetic products towards cellulose also occur (Switsur and Waterhouse 1998; Jaggi et al., 2002). A number of environmental factors (e.g. relative humidity, soil moisture, temperature, solar radiation and nutrient availability, Farquhar et al., 1989) control the balance between stomatal conductance and $\mathrm{CO}_{2}$ assimilation, which in turn influences the isotopic fractionation between atmospheric $\mathrm{CO}_{2}$ and plant matter. Owing to this influence of climatic and hydrologic parameters on plant-air exchanges and stomatal closure, local dependences of the $\delta^{13} \mathrm{C}$ of tree rings on temperature, relative humidity and more generally water stress have been found, but with a large variety of slopes (e.g. Stuiver et al., 1984; Freyer, 1979; Lipp et al., 1991; Dupouey et al., 1993; Saurer et al., 1995; Robertson et al., 1997a,b; Hemming et al., 1998; McCarroll and Pawellek 2001).

The $\delta^{18} \mathrm{O}$ of plant cellulose depends on (1) the biochemical fractionation factor $\varepsilon$ between water and cellulose (DeNiro and Epstein 1979; Sternberg et al., 1986) and (2) the isotopic composition of the water (leaf water, xylem water) used in cellulose synthesis; the isotopic composition of the precipitation is primarily driven by temperature (Rozanski et al., 1993). The leaf water isotopic composition results from the isotopic ratios of the xylem water (which is assumed to be the same as the soil water) and of atmospheric water vapour, the partial pressure of water vapour inside the leaf and at the leaf surface, the relative humidity (controlling the stomata opening) and the kinetic and equilibrium plant fractionation coefficients. During the synthesis of sugar carbohydrates such as glucose, a large isotopic exchange (typically $40 \%$ of the oxygen atoms) occurs between the sugars and the internal water, strongly imprinting the water-cellulose biochemical fractionation factor $\varepsilon$ accounting for isotopic exchanges (typically 27\%o) (Roden and Ehleringer, 2000; Roden et al., 2000). It is therefore expected that temperature (through its impact on the precipitation and therefore the soil water isotopic content) and relative humidity have large impacts on the fluctuations of tree-ring $\delta^{18} \mathrm{O}$ ratios. It is clear that changes that can affect the isotopic composition of the precipitation such as changes in moisture trajectory (or storm tracks), and changes in the seasonality of the precipitation can also have large imprints on the precipitation $\delta^{18} \mathrm{O}$ and therefore be recorded in tree-ring cellulose. Confirming the early study of Libby et al. (1976), recent studies (Werner et al., 1996; Farquhar et al., 1997; Koziet, 1997) have shown high positive correlations between wood $\delta^{18} \mathrm{O}$ and local temperature, as well as negative correlations with relative humidity (Lipp et al., 1991; Switsur and Waterhouse, 1998; Saurer et al., 2002).

Multiple environmental parameters therefore influence differently the growth of a tree and the isotopic composition of its cellulose and wood. Previous studies have shown the consistent interannual variability of $\delta^{18} \mathrm{O}$ and $\delta^{13} \mathrm{C}$ in continental locations where changes in relative humidity are the dominant environmental factor (Saurer et al., 1997, 2000). Here we explore another climatic area where a priori changes in relative humidity should be weaker due to the Atlantic ocean proximity.

Here we have analysed both the of cellulose from living oaks (Quercus robur) in Brittany, western France, and compared their interannual variability with meteorological and environmental parameters. Measurements of the combination of $\delta^{13} \mathrm{C}$ and $\delta^{18} \mathrm{O}$ in cellulose are used here in order to highlight the contribution of each isotope for the reconstruction of past environmental changes. We analyse statistically the relationships between $\delta^{13} \mathrm{C}$ and $\delta^{18} \mathrm{O}$ isotope ratios to monthly mean climatic parameters (available since 1885) and bio-climatic variables issued from water balance calculation (for 1951-1996). The good reconstruction of the water stress using tree-ring cellulose enables a study of the summer drought frequencies during the 20th century.

\section{Material and methods}

\subsection{Sampling and cross-dating}

We have sampled four living pedunculate oaks (Quercus robur) from the Rennes Forest (Fig. 1), in Brittany, western France $\left(48^{\circ} 20^{\prime} \mathrm{N}, 01^{\circ} 50^{\prime} \mathrm{W}\right)$, where meteorological data are available from the nearest weather station (Rennes-St-Jacques, located about $20 \mathrm{~km}$ to the south). Daily meteorological data are available since 1951; monthly temperature (since 1880) and precipitation (since 1885) data have been homogenized by Météo-France (Moisselin et al., 2002). The 1951-1996 mean temperatures and precipitation are typical from oceanic areas with $644 \mathrm{~mm}$ of precipitation (with a slight maxima in autumn and winter) and a

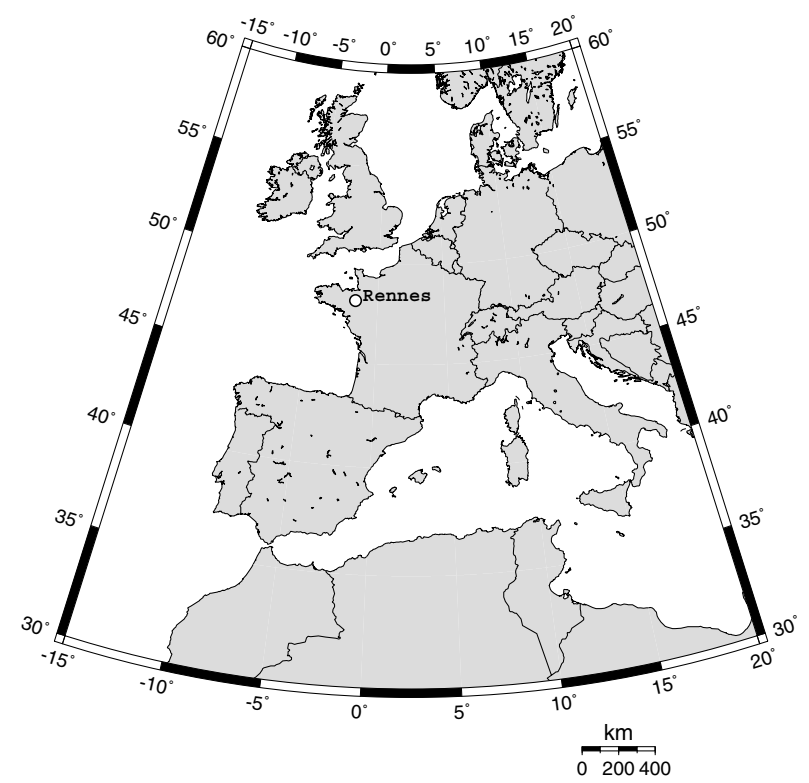

Fig 1. Map showing the location of Rennes in western Europe ( $48^{\circ} 06^{\prime}$ $\left.\mathrm{N}, 1^{\circ} 40^{\prime} \mathrm{W}\right)$. 


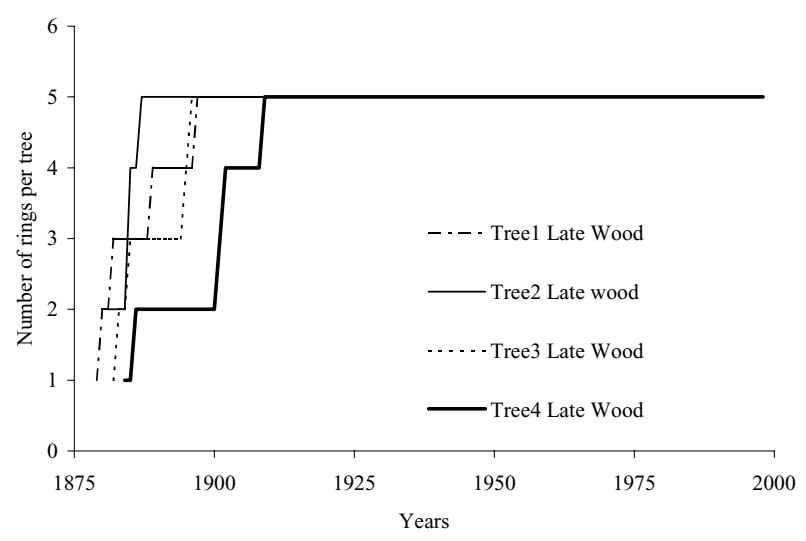

Fig 2. Number of tree rings per year used here for ring width and isotopic analyses. Five cores have been sampled from four living trees in Rennes forest and from 1909 onwards, 20 rings are available per year.

mean air temperature of $11.4{ }^{\circ} \mathrm{C}$ with a seasonal amplitude of $15.2{ }^{\circ} \mathrm{C}$. The managed high forest of Rennes essentially comprises oak stands with an understorey of beech and hornbeam. The sampled site is located in a bottom valley, with nearly no slope, and a loamy-clay and hydromorphic washed soil. Soil observations during tree sampling have shown that the average root depth of the oaks is $53 \mathrm{~cm}$, and blackish concretion levels limiting the root development reveal the underground water zone (dry in summer but wet in winter and spring, confirmed by the observation of a small temporary river during winter, spring and autumn). From root depth and textural soil analyses, the maximum water reserve is estimated to be $135 \mathrm{~mm}$, including 70 $\mathrm{mm}$ for the upper reservoir (53 cm depth). In 1998, four dominant one-century old trees were selected in the same plot on the basis of homogeneous heights (typically $\sim 21 \mathrm{~m}$ ) and diameters (perimeter of $\sim 1.10 \mathrm{~m}$ ), and five cores were taken at $1.30 \mathrm{~m}$ height in each tree.

In order to compare the isotopic signal with the growth signal, and to cross-date the different cores and the different trees, we measured the early- and late-wood width of each ring along each core (Fig. 2) (analyses performed at Nancy INRA). Although the mean ring growth is rather high $\left(2 \mathrm{~mm} \mathrm{yr}^{-1}\right)$, the inter-dating of the Rennes oaks is complicated by years with very small rings (sometimes only a few cells or only early wood). The regional representativeness of the four trees used here has been assessed by comparison with the mean growth of other trees in the same forest, available through the Renécofor network (Lebourgois, 1997). For the Rennes Forest, a mean ring width series from 1892 to 1994 has been estimated using 28 sessile oaks (Quercus petraea $L$.). The data obtained on only four trees sampled for our study are consistent with this reference growth (Fig. 3). The systematic differences result from the systematic variability of ring widths between individual trees and between different species.

\subsection{Cellulose extraction and isotopic analyses}

Only the latewood cellulose was used for isotopic analyses in order to avoid possible contamination by the photosynthesis products of the previous year, which can complicate the comparison with environmental data (Lipp et al., 1991). Prior to the cellulose extraction and analysis, the latewood was cut with a scalpel under a binocular microscope and milled with an ultra-centrifugal crusher (ZM 100) to a fineness of $<0.08 \mathrm{~mm}$. For each year, the five cores from each individual tree have been pooled together to have enough matter for the isotopic analyses. From 1879 to 1925, separate isotopic measurements were conducted on each tree, in order to track potential juvenile effects. From 1926 to 1998, the four tree annual rings have been pooled together for the analyses but every fifth year individual tree measurements were conducted in order to evaluate the tree-to-tree isotopic variability.

$\alpha$-cellulose is classically extracted in three successive steps: (1) removal of the extractives with a 1:1 toluene-ethanol mixture, (2) removal of the lignin with a $\mathrm{NaClO}_{2}$-acetic acid solution and (3) removal of the hemicelluloses with $\mathrm{NaOH}$ (Green, 1963), using the soxhlet protocol from (Leavitt and Danzer 1993). Assuming a constant systematic loss $L$ of cellulose during the extraction procedure, we calculated the effective percentage of cellulose $C$ in latewood $C$ according to the simple equation $F=C \times I-L$, with $I$ being the initial total latewood mass and $F$ the final cellulose extracted mass. This model was adjusted on 99 samples and gave an average cellulose percentage of $C=46.0 \pm 0.8 \%$ in the oak wood, a systematic cellulose loss of $L=1.4 \pm 0.6$ mg during the extraction and an average extraction yield of 43.2 $\pm 3.3 \%$

The $\delta^{13} \mathrm{C}$ and $\delta^{18} \mathrm{O}$ ratios were measured successively on the same cellulose samples (with the pooling method described above). The $\delta^{18} \mathrm{O}$ ratio of cellulose was measured using a continuous-flow method (Farquhar et al., 1997). In the method used here, an elementary analyser (Carlo Erba 1500) was coupled to a mass spectrometer (Finnigan MAT252). The sample of cellulose, packed into a silver capsule, was pyrolysed at 1080 ${ }^{\circ} \mathrm{C}$ in a helium gas stream and the products swept through a quartz tube filled with nickelized carbon $(50 \% \mathrm{Ni})$ at about 120 $\mathrm{ml} \mathrm{min}^{-1}$ (without addition of oxygen). After the pyrolysis, the oxygen-containing compounds were mainly converted to carbon monoxide (CO), the thermodynamically favoured product (Koziet, 1997). The contact between the carbon and quartz walls of the column was minimized by lining the column with nickel foil (Santrock et al., 1985). The gases were swept through water and carbon dioxide traps and a separation column and were then introduced into the mass spectrometer to measure the ratio of masses 30/28 for the CO peak. This is referenced to the 30/28 mass ratio of a $\mathrm{CO}$ reference gas introduced as a pulse at the start of each sample measurement. The calibration to the international V-SMOW standard is performed with cellulose standards (IAEA-C3; Merck; Whatmann CC31) analysed with the 
Fig 3. (a) Comparison between the mean ring width $(\mathrm{mm})$ measured from our four pedunculate oaks from Rennes forest (1879-1998) and the evolution of the average rings width $(\mathrm{mm})$ on the forest of Rennes from the 'Renécofor' network set up by INRA and ONF (French National Forest Office) on 28 sessile oaks for 1892 to 1994 (bold line). (b) Deviation between individual tree-ring width $(\mathrm{mm})$ and the mean ring width obtained for our four pedunculate oaks from Rennes forest (1879-1988). Tree 4 appears as an outlier with an annual growth significantly weaker than for the other trees during its first $20 \mathrm{yr}$.
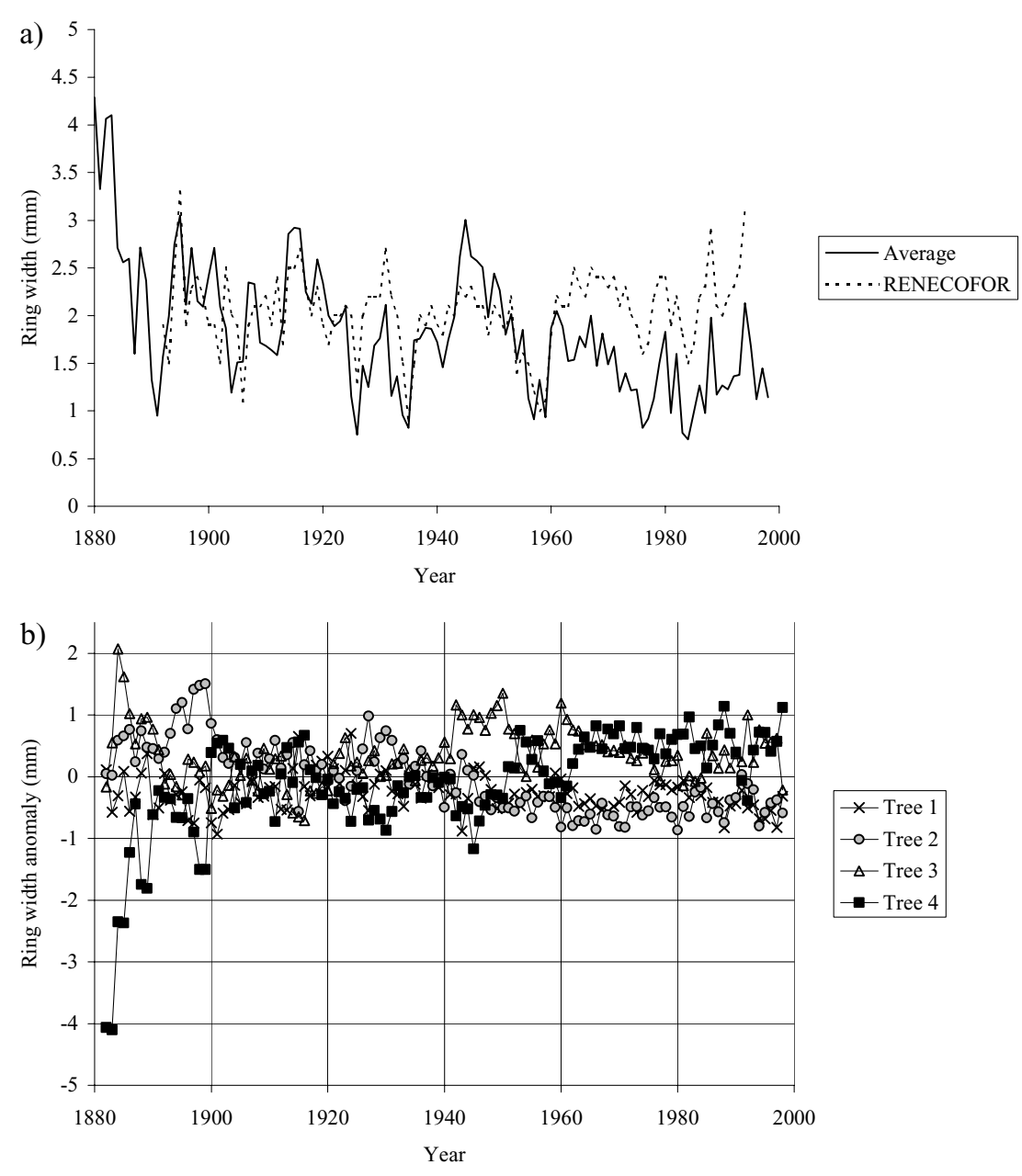

same method (two cellulose standards between four samples); the IAEA-C3 standard was assigned an $\delta^{18} \mathrm{O}$ value of $32.64 \pm$ $0.47 \%$ versus V-SMOW. The standard deviation for repeated analyses of the same $\delta^{18} \mathrm{O}$ cellulose sample is $0.27 \%$.

The $\delta^{13} \mathrm{C}$ ratio of cellulose was measured similarly with combustion and oxidation columns on an elementary analyser; the mass spectrometer measures the ratio of masses 46/44 and 45/44 for the $\mathrm{CO}_{2}$ peak referenced to the same ratios of a $\mathrm{CO}_{2}$ reference gas introduced as a pulse at the start of each sample measurement. The calibration with respect to the international PDB standard is performed with the same cellulose standards (IAEA-C3; Merck; Whatmann, CC31). The standard deviation for repeated analysis of $\delta^{13} \mathrm{C}$ cellulose is $0.18 \%$.

\section{Results and discussion}

\subsection{Tree-to-tree variability}

Figures 3 and 4 show the interannual variations of the latewood ring width, $\delta^{13} \mathrm{C}$ and $\delta^{18} \mathrm{O}$ of the cellulose, as well as the inter-tree standard deviation. As for isotopic measurements, this informa- tion is available only when individual tree measurements have been performed (each year from 1879 to 1925 and then every 5 yr). The earlywood ring width is rather constant with time and not displayed.

The variations of ring widths show one tree (tree 4) as an outlier compared with the three others with significant increasing trend from 1884 to 1909 . This tree 4 also has a specific $\delta^{13} \mathrm{C}$ signal with depleted values especially from 1884 to 1909 . By comparison, the $\delta^{18} \mathrm{O}$ signal shows much less tree to tree dispersion than ring width or cellulose $\delta^{13} \mathrm{C}$ over the whole period.

We attribute the different behaviour of tree 4 compared with the others (increase in ring width, $2 \%$ increase of $\delta^{13} \mathrm{C}$ ) to a juvenile effect possibly related to the access to a different ${ }^{13} \mathrm{CO}_{2}$ or to light availability (Francey and Farquhar, 1982; Lipp et al., 1991); interestingly, this effect is not seen in the cellulose $\delta^{18} \mathrm{O}$. It is probable that this tree (tree 4) grew under the shadow of higher trees as suggested by its cambial age (117 yr compared with 119 and $122 \mathrm{yr}$ for the other trees), and took at least $15 \mathrm{yr}$ to reach the dominant stratum.

The growth and isotopic variations recorded in the tree rings integrate: (1) effects related to the tree itself (including its 
a)

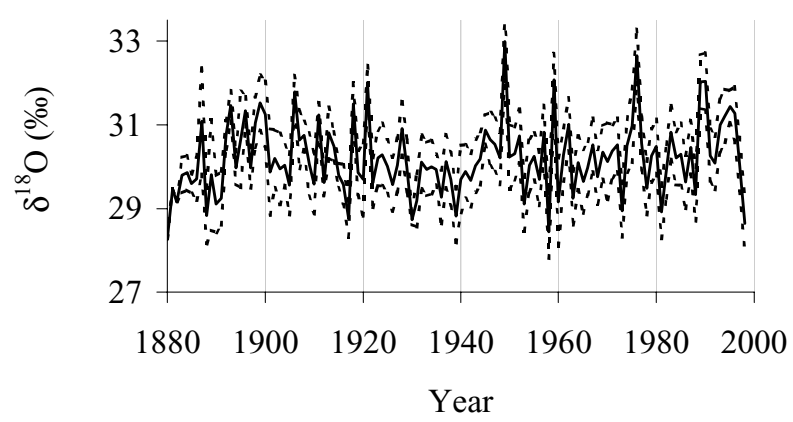

c)

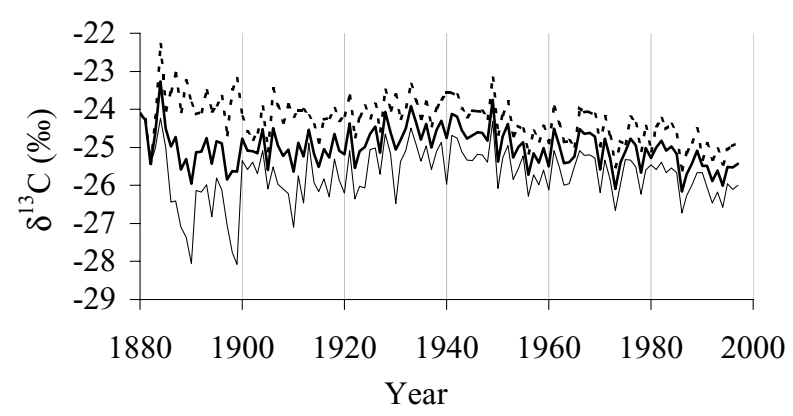

b)

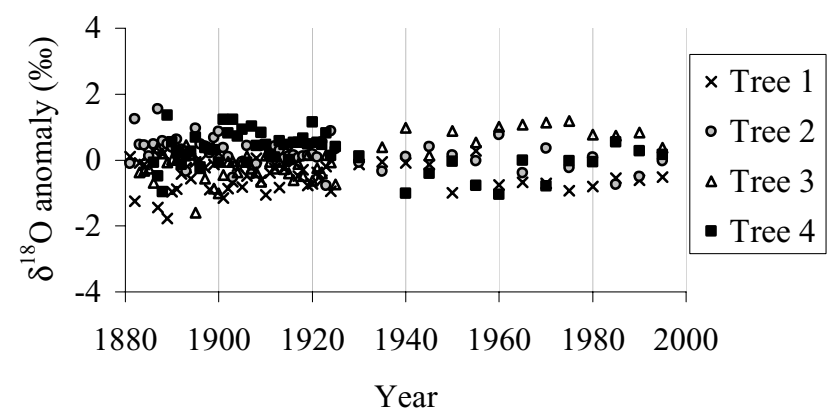

d)

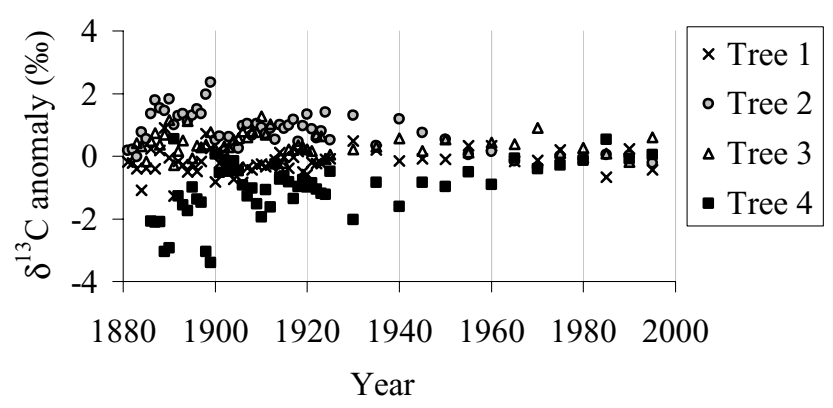

Fig 4. Year by year evolution of the cellulose $\delta^{18} \mathrm{O}$ and $\delta^{13} \mathrm{C}$ measured for each tree (from 1879 to 1925 and with a $5 \mathrm{yr}$ time step from 1925 to 1998) and measured on a pool of trees for the other years (average values). (a) Mean annual $\delta^{18} \mathrm{O}$ and annual inter-tree standard deviation (calculated from individual measurements when available; average standard deviation for measurements conducted on pooled samples). (b) Individual $\delta^{18} \mathrm{O}$ tree measurements displayed as anomalies from the four tree averaged values. (c) Same as (a) but for $\delta^{13} \mathrm{C}$. (d) Same as (b) but for $\delta^{13} \mathrm{C}$.

competition with others, the 'tree effect') and (2) the impact of forest-scale environmental conditions on the tree (climate and hydrological conditions from the previous year and the current year, 'year effect'). In order to quantify these two factors, we have analysed the variance of all the tree parameters (earlywood ring width, latewood ring width, total annual ring width, cellulose $\delta^{13} \mathrm{C}$ and $\delta^{18} \mathrm{O}$ ) (individual tree data based on five cores per tree available for 1909-1925 for and every fifth year from 1925 to 1998 , with two missing data for isotopic analyses due to the lack of material, therefore providing $30 \mathrm{yr}$ with individual tree measurements).

The variance analysis performed for individual measurements conducted when the trees are older than $\sim 30$ yr (Fig. 5) shows that the tree effect is dominant for the earlywood ring width and for the $\delta^{13} \mathrm{C}$ (43\% and $49 \%$ of the total variance, respectively), whereas most of the latewood ring width and the cellulose $\delta^{18} \mathrm{O}$ variance $(65 \%)$ is due to the year effect. Even if the number of trees sampled is small (four trees), the cellulose $\delta^{18} \mathrm{O}$ shows significantly less dispersion between individual trees than either ring width or $\delta^{13} \mathrm{C}$.

\subsection{Role of long-term change in atmospheric $\delta^{13} \mathrm{C}$ on long-term trends in cellulose $\delta^{13} \mathrm{C}$}

The fluctuations of tree-ring cellulose $\delta^{13} \mathrm{C}$ are influenced by the progressive decrease of atmospheric $\mathrm{CO}_{2} \delta^{13} \mathrm{C}(-1 \%$ o from 1951 to 1996; Mook et al., 1983; Friedli et al., 1986; Francey et al., 1995). This parallels the increase in atmospheric $\mathrm{CO}_{2}$ concentration and results from fossil fuel burning, deforestation and expansion of agriculture. When considering the relationships between cellulose isotopic composition and meteorological parameters, this long-term effect has to be corrected.

Several $\mathrm{CO}_{2} \delta^{13} \mathrm{C}$ records based on direct measurements (e.g. Keeling et al., 1995), and from firn and ice bubble air from Antarctica (Francey et al., 1999) are available, but latitudinal and seasonal fluctuations take place in the northern hemisphere mid and high latitudes. In order to correct the Antarctica data for inter-hemispheric gradients and extract the growing season (May to September) values, observed north-south gradients (1993 to 1996 from Mace Head, Ireland, $54^{\circ} \mathrm{N}$, to Amsterdam Island, $37^{\circ} \mathrm{S}$, nowadays about $0.2 \%$ ) have been extrapolated down to 


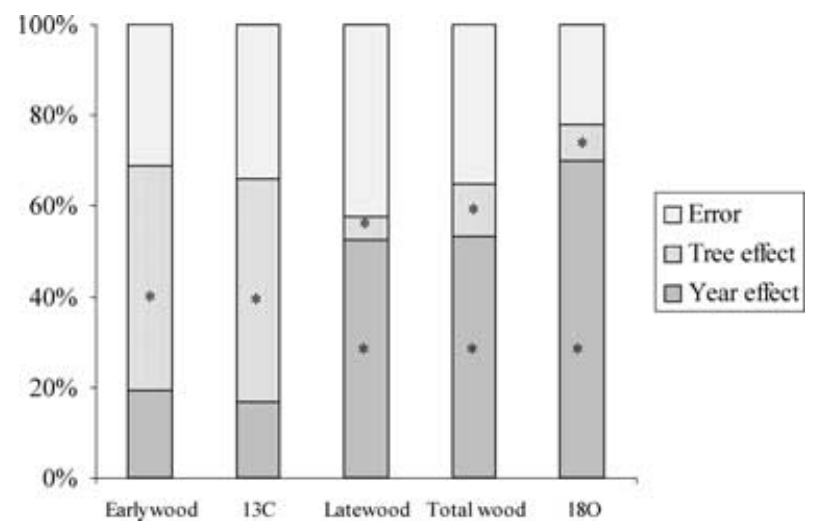

Fig 5. Variance analyses of the different tree parameters (early wood ring width, late wood ring width, total ring width, cellulose isotopic composition). The statistical analyses have been performed on the set of four trees and $30 \mathrm{yr}$ where individual isotopic measurements have been performed on 20 rings per year (from 1909 to 1921 and each 5 years from 1925 to $1995 ; 2$ yr have not been included because not enough matter was available for cellulose isotopic analysis for one of the trees, 1925 and 1930). Percentage of variance related to the year effect, the tree effect, and the residual error. Stars denote percentages for which the F-test performed for the year and tree effects to the $99 \%$ confidence level critical $F$ level.

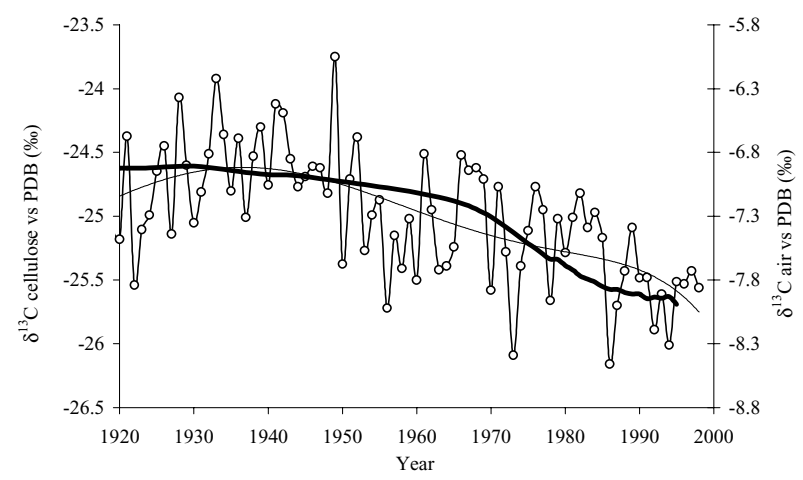

Fig 6. Temporal evolution of the $\delta^{13} \mathrm{C}$ of our tree cellulose from 1925 to 1990 (individual measurements, circle and thin line; best polynomial fit, dashed line) compared with an estimate of the atmospheric $\mathrm{CO}_{2}$ $\delta^{13} \mathrm{C}$ evolution based on high resolution ice core data from the Antarctic coast corrected from systematic differences between the two hemispheres (bold line).

1850 and added to the southern hemisphere signal (P. Ciais et al., 2000, personal communication). The resulting $\delta^{13} \mathrm{C}$ profile has been compared with Mauna Loa direct measurements (from 1978 to 1988 ) and the differences in trend represent a maximum error of $0.07 \%$ over the last $150 \mathrm{yr}$ (Trolier et al., 1996).

In our case, the values of the $\delta^{13} \mathrm{C}$ in cellulose and atmospheric $\mathrm{CO}_{2}$ decrease by $1.1 \%$ and $1.2 \%$, respectively, from 1920 to 1995 (Fig. 6). If the amplitude of the changes seem consistent, the cellulose $\delta^{13} \mathrm{C}$ shows decadal fluctuations superimposed on the slow decreasing trend, consistent with other tree-ring studies
(Wilson, 1978; Leavitt and Long, 1989; Freyer 1979; Epstein and Krishnamurthy 1990).

In the next sections, we will not use the raw $\delta^{13} \mathrm{C}$ data to compare with the meteorological and hydrological parameters but the isotopic carbon discrimination $\Delta^{13} \mathrm{C}$ defined in Section 1.

\subsection{Relationships between tree parameters and local climatic parameters}

From 1951 onwards, daily meteorological parameters are available, including relative humidity and solar radiation. A hydrological balance model (Granier et al., 1999) was run for the Rennes site using the daily meteorological parameters as input with two soil layers characterized after the in situ observations (a first layer of $35 \mathrm{~cm}$ with $58 \mathrm{~mm}$ of water reserve and $80 \%$ of the roots and a second layer of $100 \mathrm{~cm}$ with $122 \mathrm{~mm}$ of water reserve and $20 \%$ of the roots); the calculation of the potential evapo-transpiration results from the Penman formula. We have extracted from the model results the annual mean water balance parameters. Multiple linear correlations are calculated between annual or monthly meteorological and hydrological parameters and tree parameters. We discuss here correlations calculated from raw datasets, the results being in general similar to those obtained from highfrequency datasets calculated for each parameter as the deviation of the current year value from the previous year. No significant relationships were found between latewood ring width, carbon and oxygen isotopes, and the monthly meteorological parameters of the previous year; no significant correlation can be found between the different tree-ring parameters either, suggesting that these are three independent parameters in the oaks from the Forest of Rennes. The latewood width shows no clear correlation with the meteorological and hydrological parameters apart from the October temperature possibly controlling the length of the growing season.

In general, the correlation coefficients between $\Delta^{13} \mathrm{C}$ and individual meteorological parameters are not very high (typically $|R|<0.4$ ); the highest values are obtained for summer parameters: positive correlation with July relative humidity $(R=0.15)$, with the drought index $\alpha=\mathrm{ETR} / \mathrm{ETP}(R=0.40)$ (ETR actual evapotranspiration, ETP potential evapotranspiration); negative correlation with summer and autumn temperatures $(R=0.42)$ (Fig. 7). These results arise from the depletion of soil water in the Rennes forest in summer; the relative humidity and the temperature being strongly anticorrelated for the summer months ( $R=-0.67)$, cool summers being associated with more inflow of wet air and high cloud cover; the temperature thus has an indirect influence on discrimination in summer. When deprived of water the trees close their stomata, which increases the value of $\delta^{13} \mathrm{C}$ and conversely decreases the isotopic discrimination. Our results are qualitatively in agreement with previous studies but the slopes of correlation between discrimination and climatic parameters (respectively of $-0.1 \% 0^{\circ} \mathrm{C}^{-1}$ for the maximum July temperature and $0.035 \% \circ \%^{-1}$ for the July relative humidity) 


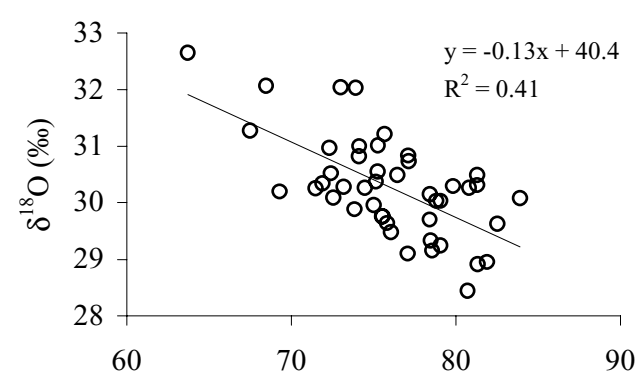

July -August relative humidity (\%)
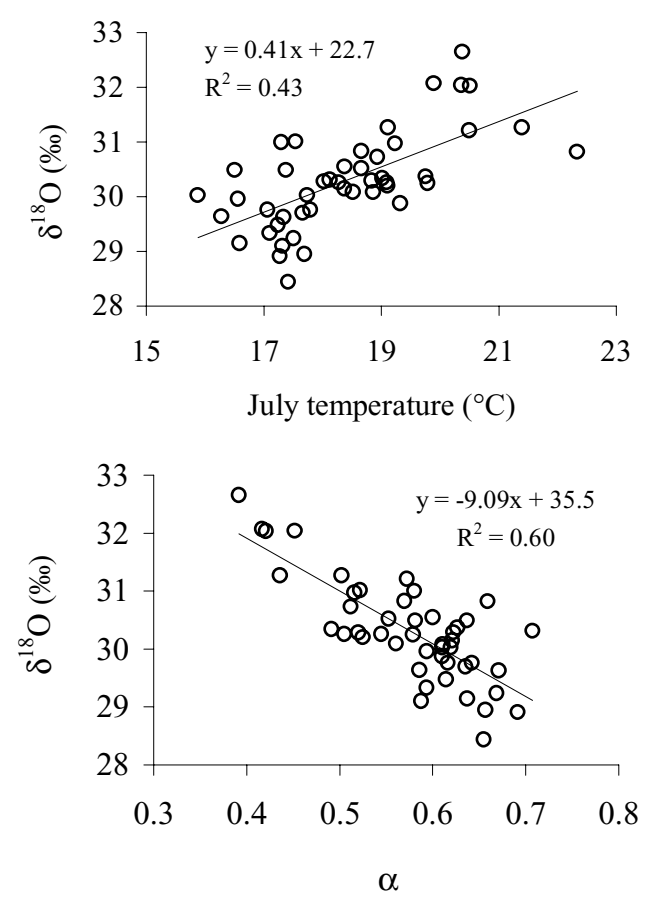

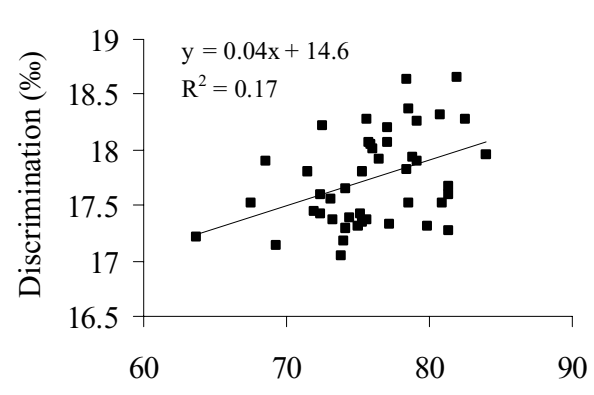

July-August relative humidity (\%)
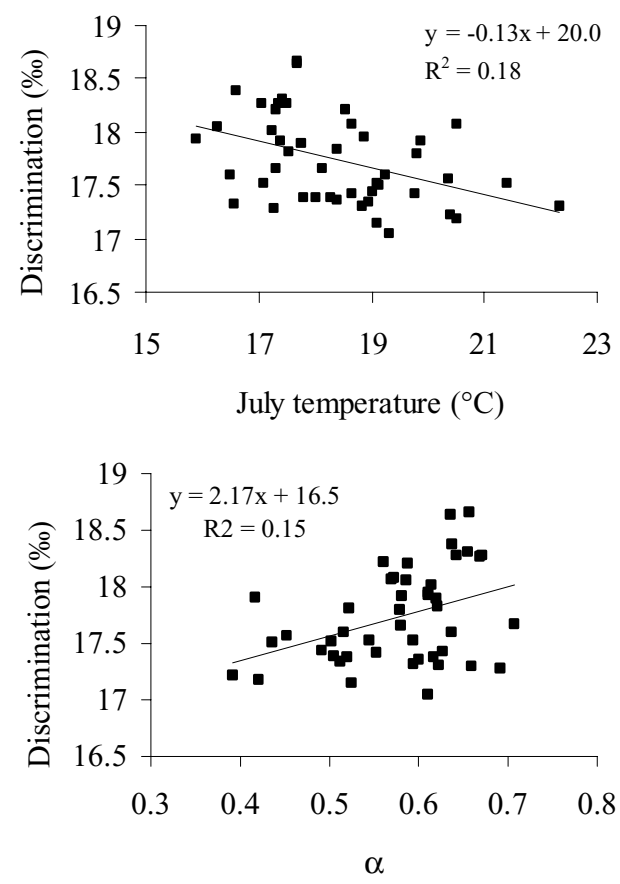

Fig 7. Linear correlation tree-ring isotopes and meteorological and hydrological parameters (1951 to 1996). (a) July-August relative humidity; (b) July temperature; (c) water stress $\alpha$.

are significantly lower than those obtained in other sites. When only high frequencies are considered, slightly larger correlations and slopes are obtained, as well as a significant correlation with April temperature possibly acting as a limiting factor during the budburst period (J. M. Guehl and G. Aussenac, 2000, personal communication).

The linear regression of the cellulose $\delta^{18} \mathrm{O}$ against climatic parameters results in much higher correlation coefficients than those obtained with $\Delta^{13} \mathrm{C}$ (Fig. 7). High correlation coefficients are obtained with summer temperature $(R=0.66)$, growing season temperature $(R=0.55)$ and annual mean temperature $(R=$ $0.52)$, and with ETP (potential evapo-transpiration) $(R=0.72)$. In contrast, anti-correlations are obtained with summer precipitation $(R=-0.37)$, summer relative humidity $(R=-0.65)$ and with the drought index $\alpha(R=-0.78)$. The dependence on temperature and the relative humidity is in agreement with previous results (Burk and Stuiver, 1981; Edwards et al., 1985).
Temperature has an indirect influence on the $\delta^{18} \mathrm{O}$ of cellulose, via the $\delta^{18} \mathrm{O}$ of the water of precipitation and the water of leaves, which affects the $\delta^{18} \mathrm{O}$ cellulose during the growing season. The relative humidity controls the cellulose $\delta^{18} \mathrm{O}$ directly by influencing the stomata thus opening the transpiration, and the evaporation on the level of the leaf and the ground. As precipitation is relatively constant all year round in Brittany, it is not surprising that there is a prevalent influence of temperature on the $\delta^{18} \mathrm{O}$ of the water. The slopes of correlation obtained between the $\delta^{18} \mathrm{O}$ and the relative humidity range between -0.08 and $-0.12 \% \circ \%^{-1}$, consistent with previous studies conducted on different species and different areas in Europe (Anderson et al., 1998; Leuenberger et al., 1998; Switsur and Waterhouse 1998; Robertson et al., 2001). With temperature, we obtain monthly slopes from June to August of between 0.23 and $0.44 \%$ o ${ }^{\circ} \mathrm{C}^{-1}$, whereas the previous studies obtain values ranging between 0.29 and $0.58 \% 0^{\circ} \mathrm{C}^{-1}$. These results show that the summer 
temperature and relative humidity have a large impact on the cellulose $\delta^{18} \mathrm{O}$. The slopes versus temperature are stronger over one season and even over the year than for months taken separately; the greatest slopes are obtained with the annual data $\left(0.7 \% 0^{\circ} \mathrm{C}^{-1}\right.$ for the average temperature). Despite all the artefacts related to the soil hydrology and tree metabolisms, the slope between the $\delta^{18} \mathrm{O}$ of cellulose and the annual average temperature is comparable with the classical spatial precipitation $\delta^{18} \mathrm{O}$-local temperature slope ('isotopic thermometer') obtained from Greenland snow $\left(0.67 \pm 0.02 \%{ }^{\circ} \mathrm{C}^{-1}\right)$ and modern European precipitation $(0.63$ $\pm 0.04 \%{ }^{\circ} \mathrm{C}^{-1}$ ) by Rozanski et al. (1993). The large imprint of summer water stress results from combined positive effects of temperature on the precipitation $\delta^{18} \mathrm{O}$, water stress on the stomata, and simultaneous enrichment of the leaf water and the soil water due to evapotranspiration.

As for the $\delta^{13} \mathrm{C}$, the correlation coefficients are larger for the high frequencies, whereas the slopes of regression are equivalent and even sometimes lower than those obtained with the raw data (not shown).

\subsection{Reconstruction of climatic parameters using all the tree growth parameters}

Both $\Delta^{13} \mathrm{C}$ and $\delta^{18} \mathrm{O}$ of the tree-ring cellulose show a large linear dependence on summer drought parameters (summer temperature, summer relative humidity and water stress $\alpha$ ), with all of these parameters being interdependent. During the calibration period from 1951 to 1996 , we have performed multiple regressions on the tree parameters in order to reconstruct fluctuations in summer relative humidity, July temperature and $\alpha$ (Table 1).

From this calibration, we can build linear regression models (coefficients given in Table 1) to reconstruct interannual variations of three climatic parameters for the period 1879-1996, assuming that the relative roles of each parameter on the tree iso- topes remains constant with time (changes in forest use may also have a significant impact on the microclimatic and environmental conditions and tree sensitivities). During the calibration period (1951-1996), the best correlation between the reconstructed and the observed parameters is obtained for $\alpha\left(R^{2}=0.61\right)$, the two other parameters (summer temperature and relative humidity) being reconstructed with $R^{2}$ values around 0.45 (see Table 1, bold correlation coefficients). As already observed in the previous section, the $\Delta^{13} \mathrm{C}$ in Rennes oaks is weakly sensitive to environmental conditions and therefore plays a minor role in the reconstruction (it accounts for about $15 \%$ of the variance for the summer relative humidity and temperature but only $4 \%$ of the variance in $\alpha$ ); the latewood ring width has an almost negligible weight in this reconstruction.

The reconstructed meteorological parameters (July-August relative humidity; July temperature; $\alpha$ ) capture both the longterm fluctuations and the extreme years observed in the homogenized datasets (Fig. 8). Long-term homogeneous meteorological data are indeed available for Météo-France Rennes St-Jacques weather station (monthly mean of the daily minimum and maximum temperatures since 1879 , monthly rainfall since 1885 ). The residual and uncorrectable breaks in rainfall series are estimated at $8 \%$ of the annual amount, because of the high spatial variability of precipitation. The residual and uncorrectable breaks in temperature series are estimated at $0.2{ }^{\circ} \mathrm{C}$. From this homogenized dataset we have also calculated the mean temperature, and several bio-climatic parameters (growing season temperature, coldest and warmest month temperature, seasonal precipitation).

The observed 5-yr running-averaged July temperature record (Moisselin et al., 2002) shows a progressive temperature warming $\left(+0.6{ }^{\circ} \mathrm{C}\right.$ century $\left.{ }^{-1}\right)$ punctuated by cold spells lasting between 5 and $15 \mathrm{yr}$ (1880-1895; around 1920, 1940, 1960 and 1980) and warm episodes (a large one between 1895 and 1905; 5-year long episodes around 1935, 1945, 1975, 1983 and after

Table 1. Multiple linear regressions performed during 1951 to 1996 on annual mean values to reconstruct the variability in drought index $\alpha=$ ETR/ETP; July-August relative humidity (h) and July temperature (T). The slopes and correlation coefficients are displayed as well as the percentage of reconstruction variance explained by each parameter.

\begin{tabular}{|c|c|c|c|c|c|}
\hline \multirow[b]{2}{*}{$\alpha$} & \multicolumn{3}{|c|}{ Ring width $(\mathrm{mm}) \delta^{18} \mathrm{O}(\% \circ)$} & \multirow{2}{*}{$\frac{\Delta^{13} \mathrm{C}(\% \circ)}{1.1410^{-2}}$} & \multirow[t]{2}{*}{ Reconstruction } \\
\hline & Slope & $-1.6610^{-4}$ & $-6.5210^{-2}$ & & \\
\hline & $R$ & 0.14 & -0.78 & 0.40 & 0.78 \\
\hline & $R^{2}$ & 0.02 & 0.60 & 0.16 & 0.61 \\
\hline & Variance $(\%)$ & $2 \%$ & $94 \%$ & $4 \%$ & \\
\hline July-August h & Slope & $-9.110^{-4}$ & -2.81 & 1.68 & \\
\hline \multirow[t]{3}{*}{$\%$} & $R$ & 0.13 & -0.65 & 0.15 & 0.67 \\
\hline & $R^{2}$ & 0.02 & 0.43 & 0.18 & 0.45 \\
\hline & Variance $(\%)$ & $0 \%$ & $85 \%$ & $15 \%$ & \\
\hline July $\mathrm{T}$ & Slope & $-4.0610^{-3}$ & 0.89 & -0.54 & \\
\hline \multirow[t]{3}{*}{$\left({ }^{\circ} \mathrm{C}\right)$} & $R$ & 0.26 & 0.66 & 0.42 & 0.68 \\
\hline & $R^{2}$ & 0.06 & 0.43 & 0.18 & 0.47 \\
\hline & Variance $(\%)$ & $6 \%$ & $79 \%$ & $15 \%$ & \\
\hline
\end{tabular}




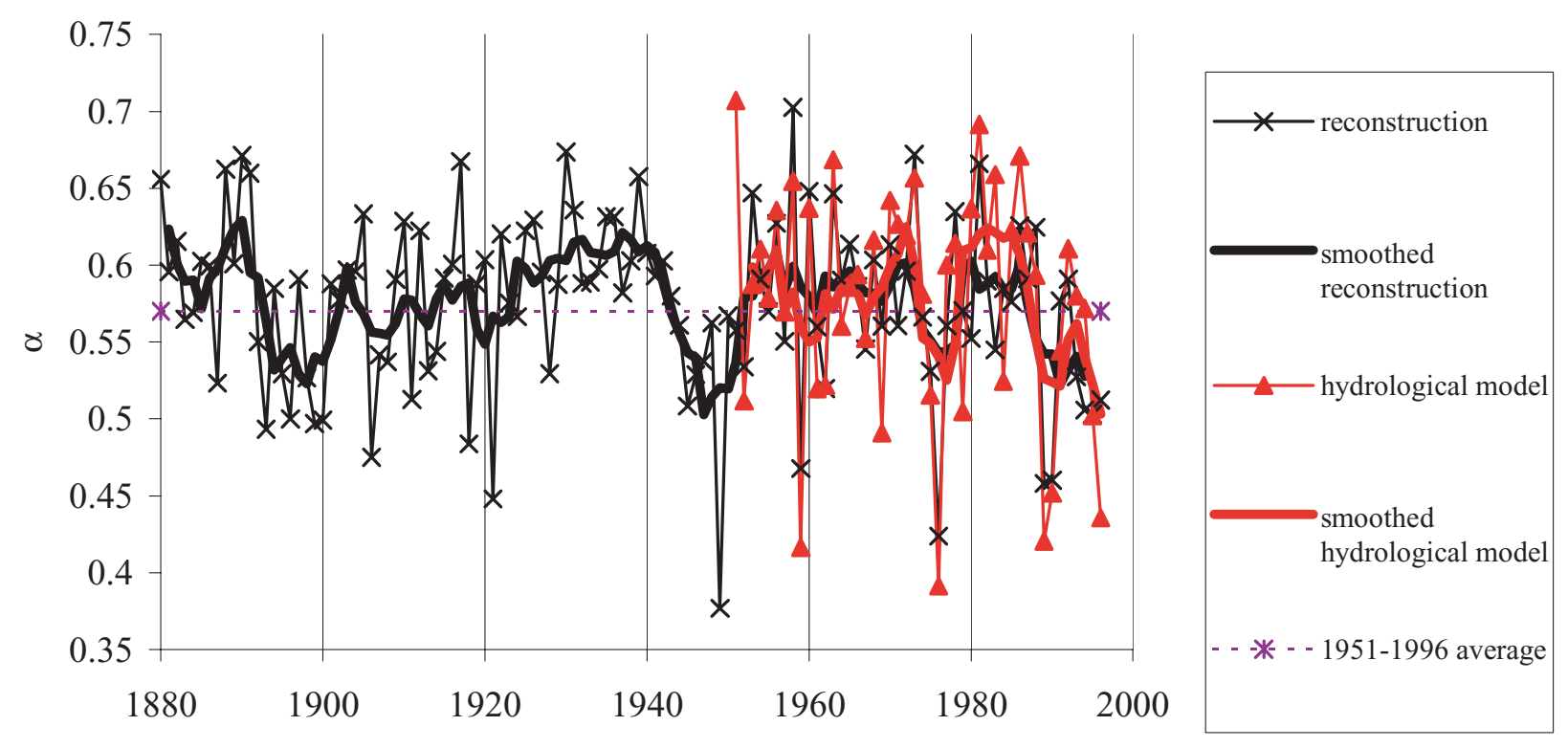

Year

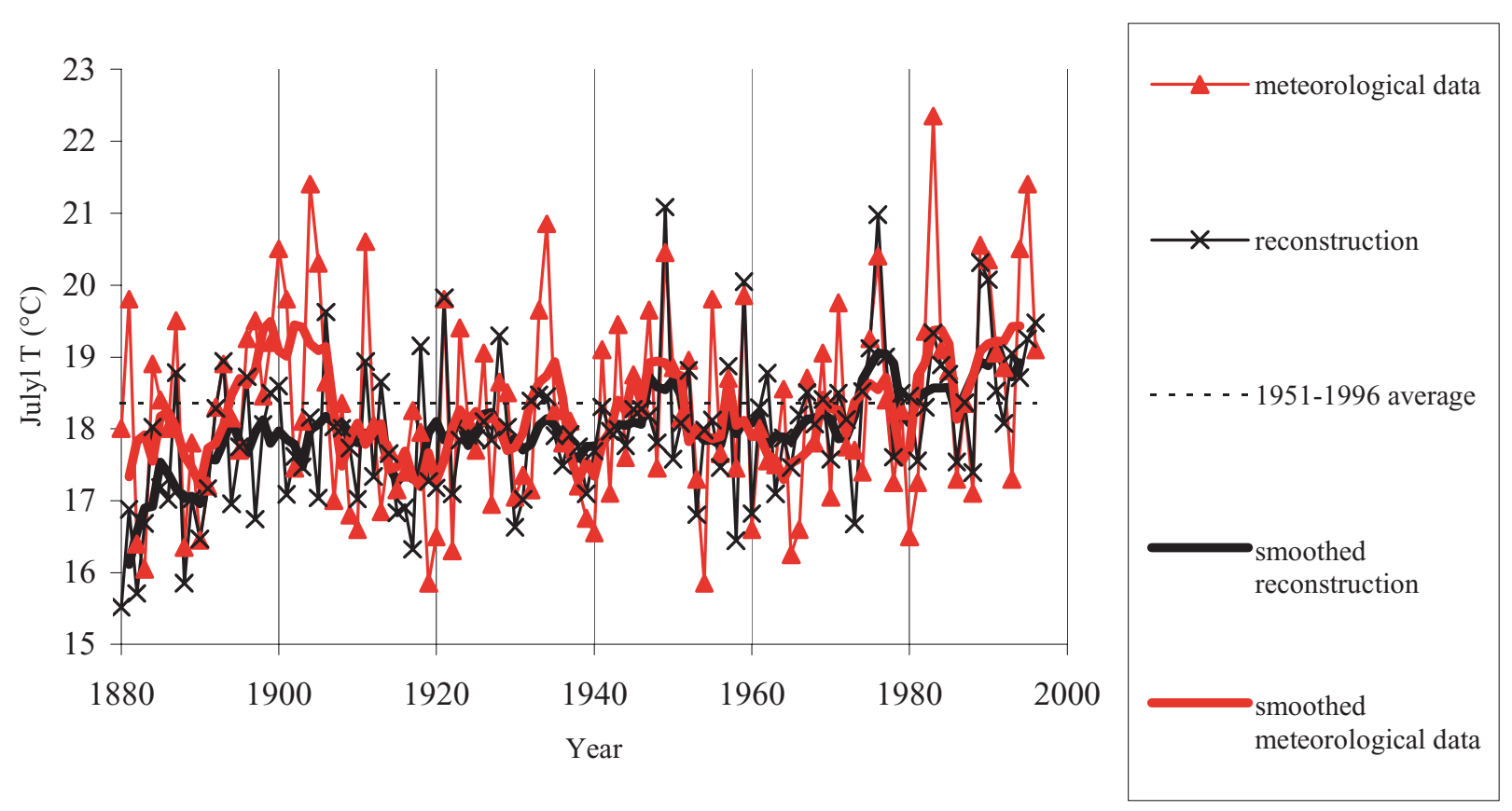

Fig 8. Comparison between annual and 5-yr running averages of reconstructed (crosses and black line) and observed (triangles and red line) climatic parameters: top) water stress $\alpha$; bottom) July temperature. The dashed line represents the 1951-1996 average values of the calculated $\alpha$ and observed July temperature.

1987). The amplitude of these pluri-annual spells ranges between 1 and $2{ }^{\circ} \mathrm{C}$. Interestingly, the reconstructed July temperature 5-yr running average (Fig. 8) is able to capture most of these changes, apart from the early 20th century warming (1895-1905), which may arise from a bias in the instrumental temperatures (it is not seen in homogenized June or August temperature datasets). Because of this, the reconstructed long-term trend shows a larger linear increase $\left(+1.1^{\circ} \mathrm{C}_{\text {century }}{ }^{-1}\right)$. Good correlations are obtained between the annual pre-1951 homogenized and reconstructed summer temperatures $(R=0.5)$ and for the 5-yr running averages of homogenized and reconstructed July temperatures $(R=0.6$ for the whole series; $R=0.8$ for the time period after 1905). We show here that the tree-ring cellulose provides a good reconstruction of both interannual and low-frequency climatic fluctuations (at least in terms of summer temperature). 
The reconstructed summer drought indices (July-August relative humidity and annual mean $\alpha$ ) indicate small decreasing trends also punctuated by long (decadal) dry and wet phases (Fig. 8): the wet phases occur between 1880 and 1890, around 1910-1915, 1920-40, 1950-70 and 1980-1985; in contrast the marked dry phases occur between 1891 and 1900, 1941-1950, 1972-1978 and since 1985. Before 1951, soil water balance calculations are not possible due to the lack of daily meteorological parameters (solar radiation, wind speed and relative humidity), which are important for the evapotranspiration calculations. The comparison between the reconstructed water stress and the available homogenized monthly temperature and precipitation data suggest a complex interplay between temperature and precipitation interannual variability. These wet and dry phases may arise from seasonal to interannual changes in moisture supply to Brittany, possibly related to oscillations of the North Atlantic pressure system (NAO). The 20th century trend obtained here for summer water stress is opposed to the slight increase in winter months and annual mean wetness estimated from the De Martonne drought index (Moisselin et al., 2002) consistent with a larger increase in winter than in summer precipitation during the 20th century.

\subsection{Identification of dry summers (extreme years)}

We have shown previously that the cellulose isotopes enable a reconstruction of summer temperature, relative humidity or water stress, which is consistent with the available observations (during the calibration period but also during the beginning of the century) in terms of decadal fluctuations and trends. Before 1951, when no soil water balance can be calculated because of the lack of daily meteorological observations (apart from temperature and precipitation), it is difficult to estimate quantitatively the frequency of summer droughts (using only monthly mean precipitation and temperature is limited). We attempt here to use the reconstructed water stress $\alpha$ from the trees to quantify the extreme dry years from 1885 to 1996 and put the recent drought frequency increase in a larger perspective.

The comparison of the 'extreme' drought years reconstructed from the cellulose parameters and estimated from the hydrological and meteorological parameters is very sensitive to the definition of the extremes. Here we define the drought years as the years for which the environmental parameters deviate from their 1951-1996 mean by more than one standard deviation. The distributions of the different parameters are not purely Gaussian (bimodal) but the results discussed here remain robust when thresholds based on the cumulative distribution (15\%) are used to identify extreme years.

In order to evaluate the realism of the dry years estimated from the tree cellulose parameters, we have compared the extreme events identified from the reconstructed summer temperature, relative humidity and water stress to the extreme years that can be identified from the observed parameters (summer temperature, precipitation amount from the previous fall to the current growing season) and calculated parameters (water stress). We have also performed tests using drought indices (De Martonne index), showing in general the same extreme years as revealed by the precipitation. Owing to different mechanisms leading to dry years, all the parameters do not necessarily coincide to identify extreme years (Table 2). Out of $112 \mathrm{yr}$ between 1885 and 1996, 39 yr appear as extremely warm and/or dry for at least one parameter, but only $17 \mathrm{yr}$ are common to at least two parameters, which we consider as robust. This is also the number of droughts identified from the reconstructed water stress, giving an average pacing of one drought for seven summers. This parameter does not capture the 1934 meteorological dry year, possibly because this results from a short dry period in August, possibly too late in the growing season to be strongly imprinted on the cellulose.

There is a large decadal variability of the frequency of the reconstructed water stress droughts with increased drought frequencies in the beginning and the end of the 20th century (on average one drought every $4 \mathrm{yr}$ ) compared with the 1930s and the 1960s-1970s, with one drought only in $20 \mathrm{yr}$. The tree-ring cellulose therefore suggests that the recent increase in drought frequencies in the 1990s is not unprecedented during the 20th century; the comparison with extreme summer temperature and bioannual precipitation extreme frequencies suggest different mechanisms being responsible for the frequent droughts in the 1940s (less precipitation) than the 1990s (warmer temperatures). The 18 extreme dry years (17 identified from the reconstructed $\alpha$ and the $1934 \mathrm{yr}$ ) correspond on average to precipitation one standard deviation lower than the 1951-1996 average and July temperature one standard deviation higher than the 1951-1996 average. They can be classified into four groups (Fig. 9): one group for which both homogenized summer temperature and growing season precipitation are extremes (1921, 1934, 1945, $1959,1989,1990)$; one group for which only the precipitation is extremely low $(1893,1906,1918)$; one group for which only the summer temperature is extremely high $(1911,1914,1976$, 1994 and 1995) and a last group where none of these two meteorological indices are extreme (1896, 1899, 1949 and 1996), suggesting that in these cases factors other than growing season precipitation and summer temperature are responsible for the drought.

The differences between the dry years identified in the monthly meteorological parameters and the cellulose isotopes may arise from either local precipitation effects or also from the distribution of the precipitation inside 1 month (for instance, a large precipitation event occurring after several dry weeks will lead to a significant monthly precipitation but without recharging the soil water reservoir). Changes in cloud cover and/or wind speed may also affect the evapo-transpiration and therefore the water stress, an effect that is not fully taken into account by considering temperature and precipitation. Lastly, non-climatic 
Table 2. Detection of extreme dry years for the available (otherwise indicated as not available as not av.) observed, calculated and reconstructed hydroclimatic parameters (reconstructed summer temperature, relative humidity, water stress $\alpha$; observed precipitation, summer temperature, relative humidity; calculated water stress $\alpha$ ). Extreme years are defined as years for which the considered parameter deviates by one (+) or two (++) 1951-1996 interannual standard deviation from the 1951-1996 average. Years in black correspond to years for which only one parameter is extreme; years in bold font when at least one reconstructed and one observed parameter are extreme; underlined years in bold fond when several parameters are extreme by more than 2 standard deviations.

\begin{tabular}{|c|c|c|c|c|c|c|c|}
\hline & $\begin{array}{l}\text { Rec. } \\
\mathrm{T}\end{array}$ & $\begin{array}{l}\text { Rec. } \\
\mathrm{H}\end{array}$ & $\begin{array}{l}\text { Rec. } \\
\alpha\end{array}$ & $\begin{array}{l}\text { Obs } \\
\mathrm{P}\end{array}$ & $\begin{array}{l}\text { Obs. } \\
\mathrm{T}\end{array}$ & $\begin{array}{l}\text { Obs. } \\
\mathrm{H}\end{array}$ & $\begin{array}{l}\text { Calc. } \alpha \\
\alpha\end{array}$ \\
\hline 1887 & & & & + & & not av. & not $a v$. \\
\hline 1892 & & & & + & & not av. & not av. \\
\hline 1893 & & & + & + & & not $a v$. & not av. \\
\hline 1896 & & & + & & & not av. & not $a v$ \\
\hline 1898 & & & & + & & not av. & not $a v$. \\
\hline 1899 & & & + & & & not av. & not $a v$. \\
\hline 1900 & & & + & & + & not av. & not $a v$. \\
\hline 1901 & & & & + & & not $a v$. & not av. \\
\hline 1902 & & & & + & & not av. & not av. \\
\hline 1904 & & & & & ++ & not $a v$. & not av. \\
\hline 1905 & & & & & + & not av. & not $a v$ \\
\hline 1906 & + & + & + & + & & not av. & not $a v$ \\
\hline 1908 & & & & + & & not av. & not $a v$. \\
\hline 1911 & & & + & & + & not av. & not av. \\
\hline 1918 & & + & + & ++ & & not av. & not $a v$. \\
\hline 1920 & & & & & & not av. & not $a v$ \\
\hline 1921 & + & + & ++ & ++ & & not av. & not $a v$ \\
\hline 1932 & & & & & & not av. & not $a v$. \\
\hline 1933 & & & & + & & not av. & not $a v$. \\
\hline 1934 & & & & + & + & not av. & not $a v$ \\
\hline 1938 & & & & + & & not av. & not av. \\
\hline 1943 & & & & + & & not av. & not $a v$ \\
\hline 1944 & & & & + & & not av. & not $a v$. \\
\hline 1945 & & & + & & & not av. & not av. \\
\hline 1947 & & & & + & & not av. & not $a v$ \\
\hline$\underline{1949}$ & ++ & ++ & ++ & + & + & not av. & not $a v$. \\
\hline 1954 & & & & + & & not av. & not $a v$. \\
\hline 1955 & & & & & & + & \\
\hline 1959 & + & + & + & & + & + & ++ \\
\hline 1969 & & & & + & & & + \\
\hline$\underline{1976}$ & ++ & ++ & ++ & + & + & ++ & ++ \\
\hline 1983 & + & & & & ++ & & \\
\hline 1984 & & & & & & + & \\
\hline 1989 & ++ & ++ & + & ++ & + & & ++ \\
\hline 1990 & + & + & + & & + & & + \\
\hline 1992 & & & & + & & & \\
\hline 1994 & & & + & & + & & \\
\hline 1995 & & + & + & & ++ & + & \\
\hline 1996 & + & + & + & & & + & + \\
\hline Total & 9 & 10 & 17 & 22 & 13 & 6 & 6 \\
\hline
\end{tabular}

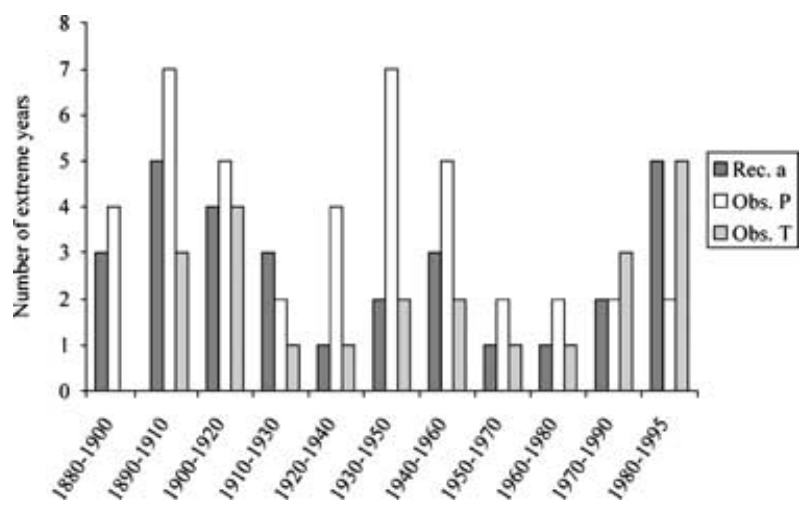

Fig 9. Frequency of dry summers in 20 -yr time periods estimated from the identification of extreme years from the reconstructed water stress, the annual precipitation from November of the previous year to October of the current year, the summer temperature.

phenomena such as intensive forest use or pathogen attacks may bias the tree-based reconstructions.

The droughts identified in the cellulose isotopic parameters and the reconstructed bioclimatic parameters (relative humidity and $\alpha$ ) can also be used to classify the droughts by decreasing amplitude and show the following results for the forest of Rennes: 1949, 1976, followed by a group of years: 1921, 1989, $1990,1959,1906,1918$ and several years from the 19th century (1893, 1899, 1900, 1896 for $\alpha$ only), followed by the droughts of the 1990s (1995 and 1996). This result is consistent with the hydrological parameters calculated for the 1951-1996 period, which identify the largest droughts of these $44 \mathrm{yr}$ to occur in 1976, 1989 and 1959. The 1980-1990 increase in drought frequencies analysed from soil hydrology in Brittany (Dubreuil et al., 1998) is not unpreceeded in the previous century. Our results suggest that any local warm climate period is also characterized by more frequent summer droughts.

In order to assess the regional significance of extreme dry summers in Brittany, we have used the 10-200 cm soil moisture diagnosed in the NCEP meteorological reanalyses from 1949 to 2002 (Kalnay et al., 1996). The fluctuations of the simulated JulyAugust soil moisture in the four grid points nearest to Rennes (with meteorological parameters consistent with the in situ measurements) exhibit a slow decreasing trend and extreme years in 1949, 1959, 1976, 1989, 1990, 1995 and 1996, in excellent agreement with our water stress reconstructions (not shown). The anomalies between each extreme year moisture relative to the 1951-1996 average (Fig. 10) show that when a drought is identified in Rennes, the soil moisture exhibits a significant deficit at least in northwestern Europe, but sometimes in all Europe (1990, 1995 and 1996). The amplitude of the changes (relative to the 1951-1996 climatology) is systematically amplified further inland (up to $20 \%$ ) compared with the small variations on the oceanic coast (Briffa et al., 1994; Lloyd-Hughes and Saunders, 2002). 


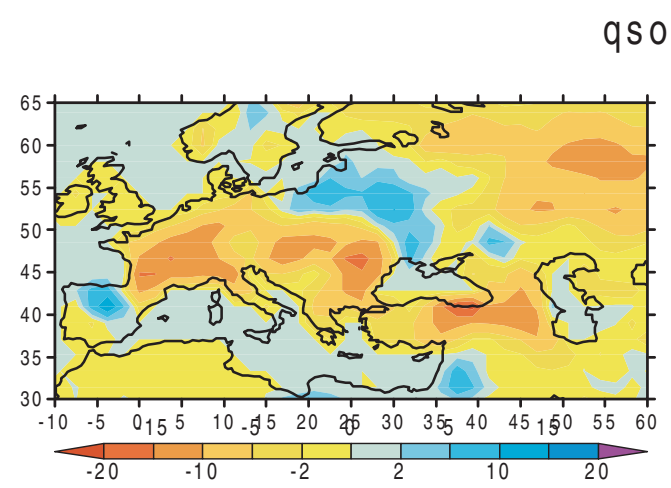

qsoilediff 49

\section{qsoilediff59}

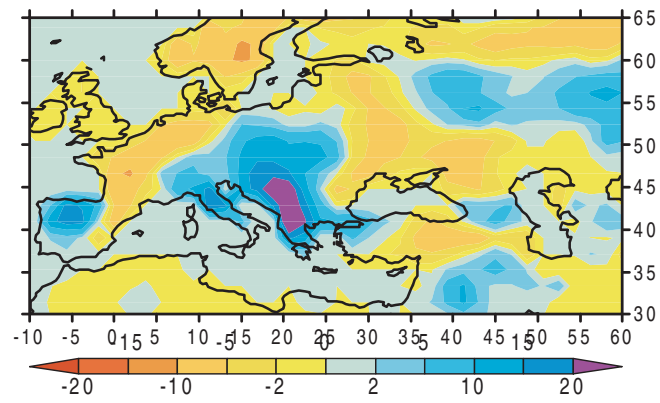

qsoilediff 76

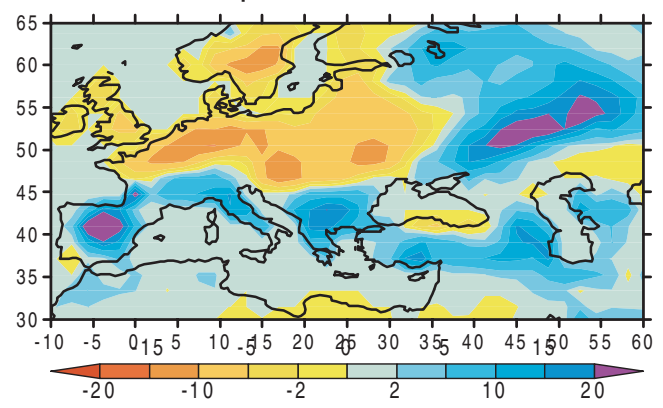

qsoilediff 89

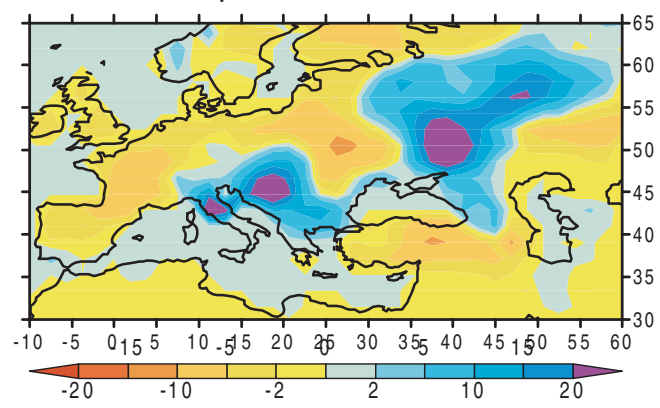

qsoilediff 90
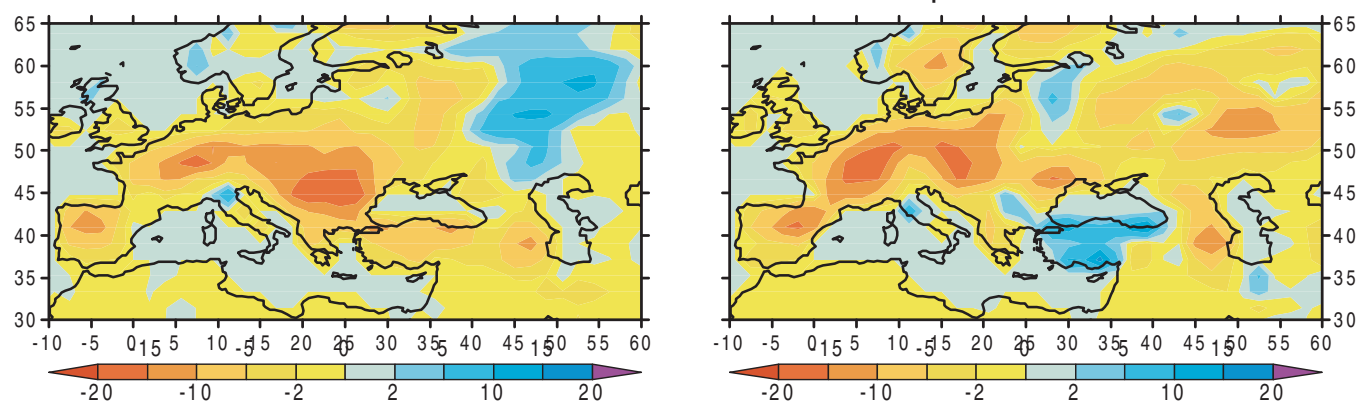

\section{qsoildiff 96}

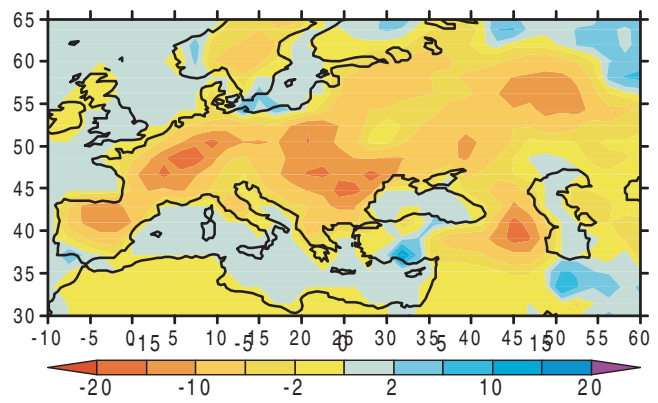

Fig 10. European distribution of soil moisture deficit (\%) for the recent extreme dry years in Rennes (1949, 1959, 1976, 1989, 1990, 1995 and 1996). For each grid point and each year, the deviation between the instantaneous NCEP soil moisture from 10 to $200 \mathrm{~cm}$ in the soil and its 1951-1996 average is centred on this 1951-1996 average. 


\section{Conclusions and perspectives}

The study of the isotopic composition of tree rings from Brittany had arisen from the lack of local climate variability time series before the instrumental period. This calibration study conducted on four trees is very promising and suggests that a significant proportion of the inter-annual climatic variability can be reconstructed using a combination of cellulose $\delta^{13} \mathrm{C}$ and $\delta^{18} \mathrm{O}$. This is not the case for the latewood ring width, which is related in a complex and weak way to the meteorological conditions, mainly to the temperature at the beginning and end of the growing season, and does not enable any climatic reconstruction here.

In Brittany, the maritime conditions result in a small seasonal variability of the climatic parameters and a large inter-annual variability of the precipitation, associated with the possibility of summer drought. The $\delta^{13} \mathrm{C}$ of the cellulose shows a century long trend that is probably associated with the decreased $\delta^{13} \mathrm{C}$ of the atmospheric $\mathrm{CO}_{2}$, mainly resulting from the burning of the fossil fuels. When corrected for this effect, the carbon discrimination shows little dependence on the meteorological parameters (possibly arising from rather stable meteorological conditions) and a significant tree to tree variability, probably associated with a juvenile effect due to competition between trees. The largest linear correlation is observed with July relative humidity, as expected from stomatal regulation. Future studies should use more trees and detailed individual tree measurements to constrain isotopic juvenile effects.

The cellulose $\delta^{18} \mathrm{O}$ from the oaks in Rennes forest shows little sensitivity to the tree and no juvenile effect; its interannual variations are strongly related to monthly temperatures, as a result of the $\delta^{18} \mathrm{O}$ of the precipitation dependence on temperature; it is also a very good marker of the summer water stresses, as all the factors explaining the cellulose $\delta^{18} \mathrm{O}$ vary in the same direction during dry summers (warm temperatures result in high $\delta^{18} \mathrm{O}$ of the precipitation; evaporation results in an increase in the soil water $\delta^{18} \mathrm{O}$; evapo-transpiration and closed stomata result in an increase in the leaf water isotopic discrimination). The best correlation is obtained with the hydrological parameters describing the soil moisture deficit, such as $\alpha=\mathrm{ETR} / \mathrm{ETP}(R=0.8)$. A better understanding of $\delta^{18} \mathrm{O}$ in tree cellulose should arise from sites where the isotopic composition of precipitation, soil, xylem and leaf waters at least have been monitored, which was not the case in Rennes.

The sensitivity of $\delta^{18} \mathrm{O}$ and $\Delta^{13} \mathrm{C}$ to summer water deficit through the relative humidity, the summer temperature or the $\alpha$ parameter enable a multi-parameter reconstruction of these bioclimatic variables, with the reconstructions explaining between 45 and $60 \%$ of the inter-annual variance. In these reconstructions, $\Delta^{13} \mathrm{C}$ has a weak impact and accounts for less than $15 \%$ of the reconstructed variance. The comparison with long-term homogenized meteorological data shows that the reconstructed parameters capture the decadal and centennial scale warm/cool or wet/dry periods (apart from a discrepancy between 1895 and
1905). The extreme years, defined by their departure from the 1951-1996 mean larger than one standard deviation, enable us to study the temporal evolution of the frequency of droughts. The results obtained from the reconstructed $\alpha$ parameter show that the average pacing between consecutive dry years is about $7 \mathrm{yr}$, and changes significantly with time, with one drought out of $4 \mathrm{yr}$ at the beginning and the end of the 20th century, and only one dry period out of $20 \mathrm{yr}$ in the 1930s and 1960s-1970s. The largest Rennes droughts of the 20th century are shown to be (by decreasing intensity) 1949, 1976, 1921, 1989-90, 1959, 1906,1918 , followed by the dry episodes of the 1990s (1995 and 1996). The progressive warming of summer temperatures is associated with a progressive increase in annual precipitation, but also an increase in the frequency of droughts between the 1960s and the 1990s. The reconstructed $\alpha$ parameter suggests that this increased frequency of droughts was not unprecedented and that successions of dry years may have also occurred at the beginning and middle of the 20th century; however, warm summers are always associated with frequent droughts. Lastly, the location of Rennes forest, near the Atlantic ocean and in the mainstream of the westerlies bringing Atlantic moisture to Europe, may explain the large geographical patterns of the deficit in summer soil moisture over at least northwestern Europe or Europe as a whole associated with local droughts. The paleoclimatic information obtained from this specific site may be relevant for extreme drought conditions over a significant geographical area.

As fossil oak trees have also been sampled in ancient buildings from the town of Rennes, these reconstructions of bioclimatic parameters will be extended to the past $400 \mathrm{yr}$ and will enable one to put the 20th century climatic evolution in a larger local perspective both in terms of long-term trends and also the frequency of droughts.

\section{Acknowledgemnts}

We thank François Geremia for his expertise in tree-ring measurements and interdating, G. Borris for the tree-ring cutting, Markus Leuenberger and Olivier Cattani for their experimental support. The stable isotope work at LSCE is supported by the Commissariat à l'Energie Atomique (CEA), the Centre National de la Recherche Scientifique (CNRS) through two programmes (Programme National d'Etude du Climat, PNEDC; and Environnement et Climat du passé, histoire et évolution, ECLIPSE), and the European Community 5th Research framework for Environment, Sustainable Development and Energy (ISONET). We thank Vincent Dubreuil, Chantal Descolas-Gros, Olivier Mestre, Jean Jouzel, Pascal Yiou, Uli von Grafenstein and two anonymous reviewers for discussions and comments on this work.

\section{References}

Anderson, W. T., Bernasconi, S. M. and McKenzie, J. A. 1998. Oxygen and carb on isotopic record of the climate variability in tree ring 
cellulose (Picea abies): an example from central Switzerland. J. Geophys. Res. 103, 31 625-31 636.

Briffa, K. R., Jones, P. D. and Hulme, M. 1994. Summer moisture variability across Europe, 1892-1991: an analysis based on the Palmer drought severity index. Int. J. Climatol. 14, 475-506.

Burk, R. L. and Stuiver, M. 1981. Oxygen isotope ratios in trees reflect mean annual temperature and humidity. Science 211, 1417-1419.

DeNiro, M. J. and Epstein, S. 1979. Relationship between the oxygen isotope ratios of terrestrial plant cellulose, carbon dioxide and water. Science 204, 51-53.

Dubreuil, V., Mounier, J. and Lejeune, C. 1998. The recent increase of summer water deficit in western France. Publ. Assoc. Int. Climatol. 11, 151-157 (in French).

Dupouey, J. L., Leavitt, S., Choisnel, E. and Jourdain, S. 1993. Modelling carbon isotope fractionation in tree rings based on effective evapotranspiration and soil water status. Plant Cell Environ. 16, 939-947

Edwards, T. W. D., Aravena, R., Fritz, P. and Morgan, A. V. 1985. Interpreting paleoclimate from $18 \mathrm{O}$ and $2 \mathrm{H}$ in plant cellulose comparison with evidence from fossil insects and relict permafrost in south western Ontario. Can. J. Earth Sci. 22, 1720-1726.

Edwards, T. W. D., Graf, W., Trimborn, P., Stichler, W., Lipp, J. and Payer, H. D. 2000. Delta C-13 response surface resolves humidity and temperature signals in trees. Gechem. Cosmochem. Acta 64, 161167.

Epstein, S. and Krishnamurthy, R. V. 1990. Environmental information in the isotopic record in trees. Phil. Trans. R. Soc. Lond. A 330, 427439.

Farquhar, G. D., Ehleringer, J. R. and Hubick, K. T. 1989. Carbon isotope discrimination and photosynthesis. Annu. Rev. Plant Physiol. Plant Mol. Biol. 40, 503-537.

Farquhar, G.D., Henry, B. K. and Styles, J. M. 1997. A rapid on-line technique for determination of oxygen isotope composition of nitrogencontaining organic matter and water. J. Rapid Commun. Mass Spectrom. 11, 1554-1560.

Francey, R. J., Allison, C. E., Etheridge, D. M., Trudinger, C. M., Enting, I. G., Leuenberger, M., Langenfelds, R. L., Michel, E. and Steele, L. P., 1999. A 1000 year high precision record of $\delta^{13} \mathrm{C}$ in atmospheric $\mathrm{CO}_{2}$. Tellus 51B, 170-193.

Francey, R.J. and Farquhar, G. D. 1982. An explanation of ${ }^{13} \mathrm{C} /{ }^{12} \mathrm{C}$ variations in tree rings. Nature 297, 28-31.

Francey, R. J. and co-authors, 1995. Changes in oceanic and terrestrial carbon uptake since 1982. Nature 373, 326-330.

Freyer, H. D., 1979. On the ${ }^{13} \mathrm{C}$ record in tree rings. Part 1. 13C Variations in northern hemispheric trees during the last 150 years. Tellus 31, 124137.

Friedli, H., Lötscher, H., Oeschger, H., Siegenthaler, U. and Stauffer, B. 1986. Ice core record of the ${ }^{13} \mathrm{C} /{ }^{12} \mathrm{C}$ ratio of atmospheric $\mathrm{CO}^{2}$ in the past two centuries. Nature 324, 237-238.

Granier, A., Breda, N., Biron, P. and Villette, S. 1999. Lumped water balance model to evaluate duration and intensity of drought constraints in forest stands. Ecol. Model. 116, 269-283.

Green, J. W. 1963. Wood cellulose. In: Method of Carbohydrate Chemistry (ed. R. L. Whistler). Academic Press, New York.

Hemming, D. L., Switsur, V. R., Waterhouse, J. S., Heaton, T. H. E. and Carter, A. H. C. 1998. Climate variation and the stable carbon isotope composition of tree ring cellulose: an intercomparison of Quercus robur, Fagus sylvatica and Pinus silvestris. Tellus 50B, 25-33.
Jaggi, M., Saurer, M., Fuhrer, J. and Siegwolf, R. 2002. The relationship between the stable carbon isotope composition of needle bulk material, starch, and tree rings in Picea abies. Oecologia 131, 325-332.

Jouzel, J., Vimeux, F., Caillon, N., Delaygue, G., Hoffmann, G., Masson, V., and Parrenin, F. 2003. Temperature reconstructions from Antarctic ice cores. J. Geophys. Res. 108, 1029-1046.

Kalnay, E., Kanamitsu, M., Kistler, W. C. R., Deaven, D., Gandin, L., Iredell, M., Saha, S., White, G., Woollen, J., Zhu, Y., Chelliah, M., Ebisuzaki, W., Higgins, W., Janowiak, J., Mo, K. C., Ropelewski, C., Wang, J., Leetmaa, A., Reynolds, R., Jenne, R. and Joseph, D. 1996. The NCEP/NCAR 40-year reanalyses project. Bull. Am. Met. Soc. 77, 437-431

Keeling, C. D., Whorf, T. P., Wahlen, M. and Plicht, J. V. d. 1995. Interannual extremes in the rate of rise of atmospheric carbon dioxide since 1980. Nature 375, 666-670.

Koziet, J. 1997. Isotope ratio mass spectrometric method for the online determination of oxygen-18 in organic matter. J. Mass Spectrom. 32, 103-108.

Leavitt, S. W. and Danzer, S. R. 1993. Method for batch processing small wood samples to holocellulose for stable carbon isotope analysis. Anal. Chem. 65, 87-89.

Leavitt, S. W. and Long, A. 1989. The atmospheric $\delta^{13}$ C record as derived from 56 Pinyon trees at 14 sites in the southwestern united states. Radiocarbon 31, 469-474.

Lebourgois, F. 1997. Dendrochronological study of the 102 network stands. Département des Recherches Techniques, Office National des Forêts, Fontainebleau, France (in French).

Leuenberger, M., Borella, S., Stocker, T., Saurer, M., Siegwolf, R., Schweingruber, F. and Matyssek, R. 1998. Stable Isotopes in Tree Rings as Climate and Stress Indicators. ETH, Zürich, $200 \mathrm{pp}$.

Libby, L. M., Pandolfi L. F., Payton P. H., Marshall, J., Becker, B. and Giertz-Sienbenlist, V. 1976. Isotopic Tree Thermometers. Nature 261, 284-288.

Lipp, J., Trimborn, P., Fritz, P., Moser, H., Becker, B., and Frenzel, B 1991. Stables isotopes in tree-ring cellulose and climatic change. Tellus 43B, 322-330.

Lloyd-Hughes, B. and Saunders, M. 2002. A drought climatology for Europe. Int. J. Climatol. 22, 1571-1592.

McCarroll, D. and Pawellek, F. 2001. Stable carbon isotope ratios of Pinus sylvestris from northern Finland and the potential for extracting a climate signal from long Fennoscandian chronologies. The Holocene 11, 517-526.

McDermott, F., Mattey, D. P. and Hawkesworth, C. 2001. Centennialscale holocene climate variability revealed by a high-resolution speleothem delta O-18 record from SW Ireland. Science 294(5545), 1328-1331.

Moisselin, J. M., Schneider, M., Canellas, C. and Mestre, O. 2002. Climatic changes over France during the 20th century; a study of longterm homogenized data of temperature and rainfall. La Météorologie 38, 45-56 (in French).

Mook, W. G., Koopmans, A. F., Carter, A. F. and Keeling, C. D. 1983. Seasonal, latitudinal and secular variations in the abundance and isotopic ratios of atmospheric carbon dioxide 1: Results from Land stations. J. Geophys. Res. 88, 10 915-10 933.

Robertson, I., Rolfe J., Switsur, V. R., Carter, A. H. C., Hall, M. A., Barker, A. C., and Waterhouse, J. S. 1997a. Signal strength and climate 
relationships in the ${ }^{13} \mathrm{C} /{ }^{12} \mathrm{C}$ ratios of tree ring cellulose from oak in southwest Finland. Geophys. Res. Lett. 24, 1487-1490.

Robertson, I., Waterhouse, J. S., Barker, A. C., Carter, A. H. C. and Switsur, V. R. 1997b. Signal strength and climate relationships in ${ }^{13} \mathrm{C} /{ }^{12} \mathrm{C}$ of tree ring cellulose from oak in east England. J. Geophys. Res. 102, 19 507-19 516.

Robertson, I., Waterhouse, J. S., Barker, A. C., Carter, A. H. C. and Switsur, V. R. 2001. Oxygen isotope ratios of oak in east England: implications for reconstructing the isotopic composition of precipitation. Earth Planet. Sci. Lett. 191, 21-31.

Roden, J. S. and Ehleringer, J. E. 2000. Hydrogen and oxygen isotope ratios of tree ring cellulose from field-grown riparian trees. Oecologia 123, 481-489.

Roden, J. S., Lin, G. and Ehleringer, J. R. 2000. A mechanistic model for the interpretation of hydrogen and oxygen isotope ratios in tree-ring cellulose. Geochim. Cosmochim. Acta 64, 21-35.

Rozanski, K., Araguas-Araguas, L. and Gonfiantini, R. 1993. Isotopic patterns in modern global precipitation. In: Climate Change in Continental Isotopic Records (eds. K. L. L. P. K. Swart, J. McKenzie and S. Savin). AGU Geophys. Monogr., pp. 1-37.

Santrock, J., Studley, S. A. and Hayes, J. M. 1985. Isotopic analyses based on the mass spectrum of carbon dioxide. Anal. Chem. 57, 14441448 .

Saurer, M., Aellen, K. and Siegwolf, R. 1997. Correlating $\delta^{13} \mathrm{C}$ and $\delta^{18} \mathrm{O}$ in cellulose of tree. Plant Cell Environ. 20, 1543-1550.

Saurer, M., Cherubini, P. and Siegwolf, R. 2000. Oxygen isotopes in tree rings of Abies alba: the climatic significance of interdecadal variations. J. Geophys. Res. 105, 12 461-12 470.

Saurer, M., Schweingruber, F., Vaganov, E. A., Shiyatov, S. G. and
Siegwolf, R. 2002. Spatial and temporal oxygen isotope trends at the northern tree-line in Eurasia. Geophys. Res. Lett. 29, 10-1-10-4.

Saurer, M. K., Siegenthaler, U. and Schweingruber, F. 1995. The climatecarbon isotope relationship in tree rings and the significant of site conditions. Tellus 47B, 320-330.

Sternberg, L. D. L., DeNiro, M. J. and Savidge, R. 1986. Oxygen isotope exchange between metabolites and water during biochemical reactions leading to cellulose synthesis. Plant Physiology 82, 423427.

Stuiver, M., Burk, R. L. and Quay, P. D. $1984 .{ }^{13} \mathrm{C} /{ }^{12} \mathrm{C}$ ratios in tree-rings and the transfer of biospheric carbon to the atmosphere. J. Geophys. Res. 89, 11 731-11 748.

Switsur, R. and Waterhouse, J. 1998. Stable isotopes in tree ring cellulose. In: Stable Isotopes (ed. E. H. Griffiths). BIOS Scientific Publishing, Oxford, 303-321.

Trolier, M., White, J. W. C., Tans, P. P., Masarie, K. A. and Gemery, P. A. 1996. Monitoring the isotopic composition of atmospheric $\mathrm{CO}_{2}$ : Measurement from the NOAA global air sampling network. J. Geophys. Res. 101, 25 897-25 916.

von Grafenstein, U., Erlenkeuser, E., Müller, J., Triemborn, P. and Alefs, J. 1996. A 200 year mid European air temperature record preserved in lake sediments: an extension of the d18Op-air temperature relation in the past. Geochem. Cosmochim. Acta 60, 40254036.

Werner, R. A., Kornexl, B. E., Rossmann, A. and Schmidt, H. L. 1996. On-line determination of $\mathrm{d} 18 \mathrm{O}$ values in organic substance. Anal. Chim. Acta 319, 159-164.

Wilson, A. T. 1978. Pioneer agriculture explosion and $\mathrm{CO}_{2}$ levels in the atmosphere. Nature 273, 40-41. 